\title{
Violent video games and morality: A meta-ethical approach
}

\section{Garry Young}

\begin{abstract}
This paper considers what it is about violent video games that leads one reasonably minded person to declare "That is immoral" while another denies it. Three interpretations of video game content are discussed: reductionist, narrow, and broad. It is argued that a broad interpretation is required for a moral objection to be justified. It is further argued that understanding the meaning of moral utterances - like " $x$ is immoral" - is important to an understanding of why there is a lack of moral consensus when it comes to the content of violent video games. Constructive ecumenical expressivism is presented as a means of explaining what it is that we are doing when we make moral pronouncements and why, when it comes to video game content, differing moral attitudes abound. Constructive ecumenical expressivism is also presented as a means of illuminating what would be required for moral consensus to be achieved.
\end{abstract}

Keywords: Constructive ecumenical expressivism; moral consensus; constructive sentimentalism; symbolic taboo activity; prohibited offline taboo activity

\section{Introduction}

When playing a single-player video game, and with reference to something within that game, suppose I were to make the following claim: "That is immoral". Within the context just described, what is the demonstrative pronoun 'that' referring to, such that I or anyone else might judge it to be morally wrong? In other words, what could there be within the content of 
single-player video games that one might find morally objectionable? Moreover, what should I or anyone else be taken to mean when uttering the proposition "That is immoral", irrespective of what 'that' is referring to? Answering these questions is important if one wishes to clarify the moral debate surrounding video game content: i.e., what it is we are meant to be objecting to (or not, as the case may be), what such an objection means, and the extent to which any objection is justified on moral grounds. The need for clarification on each of these points is therefore pre-requisite to proffering a resolution to the contentious issue of video game content and its moral or even legal prohibition (see, for example, Collier, Liddell \& Liddell, 2008; Copenhaver, 2015; Ferguson, 2008; Nauroth, Gollwitzer, Bender \& Rothmund, 2014; Rothmund, Bender, Nauroth \& Gollwitzer, in press; Sjöström, Sowka, Gollwitzer, Klimmt \& Rothmund, 2013; and Smith, 2006, for recent papers discussing video game violence and moral and legislative issues, particularly in the US and in regard to minors playing video games and/or the perception of the validity of scientific evidence informing such debate) The focus of this paper, however, will be on the morality of video game violence in the context of adults and so will not involve discussion on legislation or the exposure of minors to such content. ${ }^{1}$

Given the differing views on the morality of video games which contain enactments of (often) extreme violence (as noted above), a useful strategy to aid the continuing debate over their permissibility would be to understand at least some of the reasons for moral disagreement and, based on these reasons, come to an understanding of what is required for moral consensus to be achieved and, moreover, what form this moral consensus would take should it be achieved. If we can better understand the cause of our moral differences perhaps

\footnotetext{
${ }^{1}$ I acknowledge that some content depicting virtual violence may be available to age-appropriate adolescents: $\mathrm{M}$ rating permits 17+ years of age, for example (based on the Entertainment Software Rating Board (ESRB)). Nevertheless, I wish to establish, first and foremost, an ethical position relevant to adults exposed to video game simulated violence (even in the case of games with an $\mathrm{M}$ rating), before considering what such a position would have to say about the exposure of such virtual violence to age-appropriate adolescents.
} 
this can be used to gain greater insight into the direction we should take in any future discussion on the permissibility of violent representations within video games. In short, we need to be clear on what it is we are dealing with here.

The paper is divided into two parts. In the first part, I seek to clarify what the demonstrative pronoun 'that' is referring to in the case of the proposition "That is immoral" for now, let us call it $x$ - such that one reasonably-minded person might declare that $x$ is immoral while another might deny it. This part of the paper is largely descriptive, and seeks only to illustrate different ways in which video game content may be interpreted, based on what I am calling reductionist, narrow and broad interpretations. The examples used within this part of this paper should not therefore be taken to represent an exhaustive account of moral objections. What they do provide is (a) examples of different properties believed to be realized by different interpretations of video game content (but not all potential properties), and (b) material (qua these realized properties) for the second part of this paper, at least in terms of a broad interpretation of video game content, which is the position I am aiming to establish by the end of Part 1.

To be clear, then, it is my contention that only a broad interpretation of video game content permits the realization of properties that warrant moral scrutiny; although I accept that there are different ways to (broadly) interpret $x$ and that these different interpretations will realize different properties. How this affects our moral judgements - that is, whether one asserts that $x$ is immoral (or not), based on one's interpretation of $x$ and the properties it realizes - will be discussed in the second part of the paper. In Part 1, although I may comment on the fact that certain interpretations of video game content have led to certain moral judgements, and although my aim in this section is to reject the reductionist and narrow interpretations and establish the broad interpretation as necessary for moral scrutiny, I wish to leave more detailed discussion of a normative nature until Part 2. 
In Part 2, I consider the meaning of moral utterances like " $x$ is immoral". Does the meaning of such a proposition stem from the fact that, under a particular sort of broad interpretation, it is describing a categorical moral truth (for example), or is it instead an expression of one's attitude towards $x$ ? If the latter - which is the view that will be taken here - then how is moral consensus achievable in the absence of (i) shared interpretation and (ii) shared attitude, and what would moral consensus achieve anyway? To reiterate, understanding what it is that we are doing when we make moral pronouncements about video game content should help clarify why moral consensus is not currently forthcoming (Ferguson, 2010), and help illuminate what is required for consensus to be achieved. Whether moral consensus is sufficiently robust to constitute a normative position with regard to video game content will then be considered.

With regard to establishing a normative position, elsewhere, I have argued against moral realism and in favour of constructive ecumenical expressivism (see Young, 2014). It is not my intention to repeat this anti-realist argument here, although it is important to present the case for constructive ecumenical expressivism in more detail. Therefore, in addition to clarifying what the demonstrative pronoun is referring to when one utters "That is immoral", and in addition to arguing that different people may well be referring to different things when making moral pronouncements about the same virtual event, a further aim of the second part of this paper is to show how constructive ecumenical expressivism is not only able to explain the meaning of moral utterances but why, given this meaning, there is moral disagreement in the case of video game content. It is my contention that constructive ecumenical expressivism is able to provide insight into how moral agreement might be achieved. It is my further contention that such an approach is therefore able to aid continuing debate and perhaps even future legislation on video game content (although discussion on legislation is beyond the scope of this paper). 


\section{Part 1: Three levels of interpretation}

\subsection{A reductionist interpretation}

Fundamentally, $x$ is nothing but the manipulation of pixels (see Klimmt, Schmid, Nosper, Hartmann \& Vorderer, 2006, p.313). Thus, when playing a video game in which it is possible (virtually) to kill children (e.g., BioShock) $)^{2}$ or sexually assault/rape women (e.g., RapeLay) or massacre innocent people in an airport (e.g., Call of Duty: Modern Warfare 2), where these activities are described using a reductionist interpretation - as nothing but the manipulation of pixels - one might find it hard to justify the claim that $x$ (qua the manipulation of pixels) is immoral. For just as one might struggle to find the offence in a joke about torture if the comedian's utterance were to be described simply in terms of the manipulation of sound waves - after all, how can the manipulation of sound waves be offensive (or a joke, for that matter)? - one might likewise struggle to locate the legitimate object of moral inquiry in any of the above examples when presented solely as the manipulation of pixels.

This reductionist strategy has been employed as part of an amoralist rebuttal of attempts to make moral pronouncements about the content of video games (see Young, 2013). Such an approach has limited appeal, however, and tends to be easily quashed by the fact that computer-generated pixels or sound waves (qua the vocalisation of a language), or even the ink on the page which forms words, are all examples of representational vehicles (Dretske, 1995). What is 'carried' by these vehicles is representational content, and this is

\footnotetext{
${ }^{2}$ Within the game, the 'children' are in fact creatures called Little Sisters. They do, however, resemble young girls.
} 
meaningful. Representational content, in being meaningful, is a legitimate target for moral scrutiny (Powers, 2003).

\subsection{A narrow interpretation (of meaning)}

In the case of Postal 2 (for example) - a video game said to contain some of the highest levels of virtual violence available commercially (if not the highest level) ${ }^{3}-$ the representational vehicle (qua computer-generated pixels) is used on numerous occasions to represent the murder of innocent people. Similar representational content can be found in a number of other video games (e.g., the Manhunt and Grand Theft Auto series, to name two leading exponents; and, more recently, Hatred). What is being represented by these pixels is an example of what Young (2013) calls prohibited offline taboo activity (POTA): a term I shall adopt here. POTAs refer to any offline (qua real-world) taboo activity: e.g. murder, assault, paedophilia, bestiality, incest, etc. The virtual enactment of murder is arguably the most common POTA represented within violent video games. Other enactments include assault and torture, even rape. Collectively, following Whitty, Young \& Goodings (2011), I shall refer to these as symbolic taboo activities (STAs). Where $x$ is the virtual enactment of a POTA (e.g., the sexual assault of a virtual character), to declare " $x$ is immoral" is to declare that that particular STA is immoral. What is the basis for this claim and, given this basis, is the claim justified?

By way of a response, let us focus on video game representations of murder. Following Di Muzio (2006), it would be unsound to hold that such content is immoral simply because it

\footnotetext{
${ }^{3}$ See http://uk.askmen.com/top_10/videogame/top-10-most-violent-video-games_1.html (accessed 15/4/14)
} 
depicts extreme violence and therefore represents a POTA (see also Staiger, 2005, p.171). ${ }^{4}$

As Di Muzio notes:

$[\mathrm{O}]$ ne would want to resist the thesis that it is wrong to read and enjoy Homer's Iliad because it contains violence, gore and death. Depictions of violence do not per se belong in the category of the morally objectionable only because many instances of real violence do. (2006, p.280)

In keeping with Di Muzio's example, if we adopt a narrow interpretation of STAs, then the type of enactment mentioned above, with reference to video games like Postal 2, is simply the virtual enactment of actual prohibited behaviour (an STA depicting a POTA). But in representing a POTA, the STA does not possess intrinsic immoral properties; there is nothing inherently immoral in the act of representing murder, for example. ${ }^{5}$ A common way of morally objecting to STAs therefore involves moving beyond a narrow interpretation. As a segue into this broader interpretation, then, let us consider what Di Muzio means when he says that we would want to "resist the thesis that it is wrong to read and enjoy Homer's Iliad because it contains violence, gore and death" (ibid.).

It is possible to enjoy the Iliad for reasons other than that it contains depictions of violence, gore and death. For some, it may be possible to enjoy the Iliad despite the violence.

\footnotetext{
${ }^{4}$ Of course, Hume ([1739] 1978) would argue that no objects (whether representations or otherwise) have inherent (im)moral properties (See Section 2.3).

${ }^{5}$ One may object to the claim that there is nothing inherently immoral in representing murder or other POTAs. As evidence for this rebuttal, one might cite examples of 'gore porn' (Tait, 2008) - that is, reality Internet sites which show graphic real-life footage of crime scenes, road traffic accidents, executions or suicides (etc.) - or even art exhibitions such as Body World which present for viewing the skinned dead bodies of consenting adults in various 'artistic' poses (Moore \& Brown, 2007). In response to such an objection, I would still argue that the moral objection is not based on any inherent immoral property of the representation but on the broader context: in this case, the purpose of the site or presentation. Is it to satisfy ghoulish delight or is its purpose educational? The former is vulnerable to a charge of immorality, the latter less so (if at all). A similar argument (regarding purpose) has been made in the case of 'dark tourism' (Lennon \& Foley, 1996); Stone, 2006): namely, the marketing of sites of death/atrocities as tourist destinations (e.g., Auschwitz-Birkenau, the former site of the twin towers in New York, the killing fields of Cambodia). In addition, any broader context should also include the age of the viewer (minor or adult).
} 
Nevertheless, I accept that there are those who enjoy it because it contains such depictions. But even if one enjoys the book for the latter reason, the Iliad is not simply a book about violence, gore and death even if it depicts this in abundance. A similar view is expressed by Kreider (2008) when discussing works of art. Kreider argues that "most people would agree that an artistic context does justify or at least mitigate some things that we would otherwise find objectionable" outside of that context (2008, p.153). Likewise, Poole (1982) claims that the depiction of "morally and emotionally shocking situations might be tolerable if the author intended to create a work of art" (p. 40).

In contrast to these mitigating (art-related) circumstances, or simply by way of adopting a different broader interpretation, one might object on moral grounds to video games like Postal 2 or the Manhunt series, Hatred (etc.) because they "not only contain representations of violence and death, but are devoted primarily or solely to representing violence and death" (Di Muzio, 2006., p.281; emphasis in original) to the extent that such video games, one might argue, "makes the point of having no moral point" (ibid., p.290). ${ }^{6}$ Of course, one might retort: Is intentionally (or otherwise) having no moral point an immoral thing to do? In claiming that an STA is not immoral, one does not have to champion the moral value of STAs or video games that are devoted to their expression. One could accept that STAs are not morally praiseworthy, but this does not entail that they are morally bad and therefore should be morally condemned. After all, one might consider STAs to be amoral (based on one's interpretation, of course).

Instead of a criticism based on negation, then - whereby one objects to the absence of moral worth - or instead of simply objecting to the alleged fact that such games are focused solely on representations of violence and death (which implies a lack of moral worth), one

\footnotetext{
${ }^{6}$ Di Muzio's argument was originally directed against 'slasher' films such as the Texas Chainsaw Massacre. However, it seems clear to me that the same argument can be applied to video games like Postal 2.
} 
might criticize certain gaming content on the basis of what it appears to promote, especially in virtue of the simulated actions it affords. In other words, virtual content (including what we are afforded the opportunity to do) is not morally problematic simply because it depicts violence; rather, it is morally problematic whenever (and therefore because) it conveys or appears to convey the idea that one should delight in murder and other forms of extreme violence. Such an objection is based on $a$ broader interpretation of STAs.

To illustrate the form this objection might take, in 2011 the British Board of Film Classification (BBFC) refused to issue a classification for the film Human Centipede II because, in their view, the film focused on: "the sexual arousal of the central character at both the idea and the spectacle of the total degradation, humiliation, mutilation, torture and murder of his naked victims" (see Shoard, 2011, p.1). The BBFC's objection signalled that a representation can be proclaimed morally wrong because of what it intends to promote; in this case, that we should delight in the morally proscribed. Similarly, in the case of the video game, Manhunt 2 (some years earlier), the BBFC objected to some of its content owing to (again, in their view) the representation of "casual sadism" and the game's "unrelenting focus on stalking and brutal slaying", as well as the fact that the gameplay "constantly encourages visceral killing” (MailOnline, 2007, p.1).

It would seem that when adopting a narrow interpretation, one could argue that representations of extreme violence (whether they appear in a book or a play, a film or even a video game) are not in and of themselves immoral, as Di Muzio (2006) makes clear. They do not possess intrinsic immoral properties. Nor, I contend, for a claim of 'immoral' to be upheld is it enough simply for a representation within a video game to be devoid of moral worth. Instead, one way for the term 'immoral' to be applied is to adopt a broader interpretation of $x$ and hold (for example) that the purpose of the representation is to commend us to delight in that which is immoral. Given that an STA is a representation of a 
POTA, where one is commended to delight in what the STA represents, therein lies the immorality, or so one might argue.

In the Section 1.3 and 1.4 , I present two properties which one might identify as properties one finds morally objectionable, one of which I have already introduced above: namely, 'commending one to delight in what the STA represents'. The other (presented in 1.4) is a property broadly construed as 'that which has a detrimental effect on the human condition'. These two properties are used for illustrative purposes only and are in no way meant to be exhaustive of the potential properties available under a broad interpretation, as I shall make clear in Part 2.

\subsection{Using a broad interpretation: An a priori argument}

An STA is a fiction - a make-belief - which amounts to the virtual enactment of a POTA. Prima facie, the author of the fiction (the game-designer) is inviting the player to makebelieve some event: say, that I (in the guise of an avatar and within the fictional world) brutally assault and slay a number of innocent people represented by non-player characters (NPCs). However, based on a broader interpretation of the STA, in which the virtual enactment is said to realize the property broadly construed as 'commending one to delight in the idea of what the STA represents', one may object on moral grounds to the virtual content. More formally, one may object, morally:

1. (a priori) Whenever an STA is used, either overtly or covertly, as a means of commending one to delight in the idea of what the make-believe represents: namely, the corresponding POTA. 
Where commercially available gaming content invites us to make-believe extreme acts of violence, there is nothing to indicate that the game designer is using the make-believe to promote their actual beliefs (overtly or covertly). Nevertheless, one might still wish to claim that a reasonable interpretation of the content of such violent video games would lead one to believe that it is commending us to delight in the idea of such acts for real; or even, at the very least, that such virtual content is vulnerable to misunderstanding. As such, one could argue that where the likelihood exists that the make-belief could be misconstrued as endorsing (1) then this is sufficient, morally, to condemn the STA. Either way, the point I am making is that, under different but similarly broad interpretations, what one believes the virtual enactment is realizing is a particular property that one finds morally objectionable (a point I will return to in Part 2).

\subsection{Using a broad interpretation: An a posteriori argument}

Where it is not the game designer's intention to commend me (or anyone) to delight in what the STA represents, and where I do not reasonably interpret or even misconstrue this to be the case, nevertheless, when playing a video game like Postal 2, even if it is just for its entertainment value (see Nys, 2010), as a result of engaging in such make-believe I may come to delight in the idea of violence for real. This seems to be part of the reasoning and therefore concern behind the BBFC's objection to Human Centipede II (mentioned earlier) and even aspects of British obscenity law (see Young \& Whitty, 2012). In addition, such reasoning forms the basis for virtue theory objections to violent video games: grounded on the idea that the simulation of vice will lead to moral corruption (see McCormick, 2001). Proponents of such an objection (or even similar consequentialist-style objections based on 
negative utility: see Markey \& Markey, 2010; Schulzke, 2010; Singer, 2007; and Waddington 2007), often cite research findings which correlate playing violent video games with increases in various forms of anti-social behaviour, or decreases in one's sensitivity to such behaviour or propensity to engage in pro-social behaviour (Adachi \& Willoughby, 2011; Anderson, 2004).

It would be erroneous to ignore findings supporting the view that playing violent video games is associated with increased violent or otherwise anti-social behaviour (Greitemeyer \& Mügge, 2014). Anderson, Shibuya, Ihori, Swing, Bushman, Sakamoto et al. (2010), for example, on completing a meta-analytic review of literature on video game violence and its effects, claimed to have found that exposure to video games with violent content is a causal risk factor for increased aggressive behaviour, cognition, and affect, and decreases empathy and prosocial behaviour. Ferguson (2007a, 2007b), however, in his meta-analytic review on video game violence, warns us to treat many of the findings supporting a connection to antisocial behaviour with caution, arguing that the measures of aggression used in most studies lack validity and that often the effect sizes are close to zero. He also suggests that there is a bias in the academic literature in favour of those papers which report statistically significant differences between groups. Because of this, and based on conflicting evidence found in the literature, any attempt to posit a direct causal link between video game content and violent (real-world) behaviour should be regarded as overly simplistic, largely uncorroborated, and ultimately contentious. Indeed, for dissenting voices and further critical discussion on Anderson et al.'s conclusion, see Bushman, Rothstein and Anderson (2010); Ferguson and Kilburn (2010); and Huesmann 2010 (see also Bensley \& Van Eenwyk 2001; and Ferguson 2011). Moreover, Markey, Markey and French (2014) following a meta-analytic review of data, including FBI crime statistics and video game sales, report: 
Contrary to the claims that violent video games are linked to aggressive assaults and homicides, no evidence was found to suggest that this medium was a major (or minor) contributing cause of violence in the United States. Annual trends in video game sales for the past 33 years were unrelated to violent crime both concurrently and up to 4 years later. Unexpectedly, monthly sales of video games were related to concurrent decreases in aggravated assaults and were unrelated to homicides. (pp.14-15)

In terms of the findings of research currently undertaken, then, there is no consensus on what the effects of playing violent video games are (see Ferguson, 2013; but also Bushman, Gollwitzer \& Cruz, 2015, Bushman \& Huesmann, 2014, and Krahé, 2014, for a rebuttal of Ferguson's claims, and therefore as a means of reinforcing my argument for a lack of consensus). ${ }^{7}$ Having said that, one may nevertheless feel justified in objecting morally:

2. (a posteriori) Whenever engaging in an STA is shown to result in a detrimental effect on the human condition such that, irrespective of (1), one acquires (for example) the propensity to delight in the idea of POTAs generally or the corresponding POTA in particular.

In the case of (2), the focus of the moral objection is the effect enacting particular content has. This can occur in conjunction with (1) but need not: for (2) can be satisfied logically and

\footnotetext{
${ }^{7}$ Although my interest in this paper is directed at adult engagement with video games, one may nevertheless wish to contrast any alleged risks associated with playing violent video games, particularly for children in the US, with the comparatively increased risk associated with playing (American) football (I thank the anonymous reviewer for drawing my attention to this point). Boden, Breit, Beachler, Williams, and Mueller (2013) recorded the number of reported child fatalities associated with playing (American) football during the period 1990-2010. They found around 12 fatalities occurred per year during this period. In addition, see Shankar, Fields, Collins, Dick \& Comstock (2007) for a report on the number of school and collegiate fractures and concussions reported during the 2005-06 season.
} 
empirically independently of (1). Someone who endorses (2), in effect, believes that a given STA realizes a property which (broadly construed) is 'detrimental to the human condition'.

\subsection{A brief review}

Returning to the utterance "That is immoral". In the context of single-player video games, what the demonstrative pronoun refers to is dependent on one's level of interpretation. Therefore, where moral pronouncements appear to differ - such that A may declare that to be immoral and B may hold that not to be immoral - this does not necessarily denote a difference in one's moral stance; rather, it may simply be the result of differing interpretations of what 'that' represents based on a reductionist, narrow or broad interpretation. I quickly dismissed reductionist and narrow interpretations of video game content in favour of a broad interpretation, which I claimed was the only interpretation suited to moral scrutiny.

Imagine, then, that $\mathrm{A}$ is adopting a broad interpretation of some virtual gaming event - say, the random murder of a passerby - whereby the STA (random murder) is taken to be commending one to delight in the idea of actual murder (or is in danger of being misinterpreted as promoting this); it is believed, by A, to realize this property. B does not hold that the virtual event is immoral because B does not interpret the event in the same way. In contrast to A, B does not believe that this property is realized. In failing to concur with A that "That is immoral", B is not necessarily failing to share A's view that commending one to delight in the idea of murder is immoral; rather, it is that B does not accept that this is how one should interpret the virtual event and therefore that such a property is realized by this virtual enactment. The point of this example is that it highlights how seeming moral disagreement could in fact stem from a lack of consensus regarding the object of the moral 
judgement - expressed, in this case, as a failure to agree on what the demonstrative pronoun ('that') is referring to - and not necessarily from differing views on morality.

In the next part of this paper, I consider what it means to declare that "That is immoral". I do this, initially, irrespective of one's particular broad interpretation of what that is referring to. Next, I aim to show how the explanation proffered for the meaning of a moral utterance - notably, constructive ecumenical expressivism - not only helps account for why, using a broad interpretation, there is a lack of moral consensus when it comes to video game content, but provides insight into what is required for consensus to be achieved.

\section{Part 2: Towards a normative account}

\subsection{Constructive ecumenical expressivism}

Constructive ecumenical expressivism, very much like its forerunner - ecumenical expressivism (Ridge, 2006) - holds that, when uttered, the proposition "That is immoral" reveals two interrelated facts about the mental states of the subject. The first concerns an attitude. The second relates to a particular belief that is said to make anaphoric reference to this attitude. ${ }^{8}$ Importantly, though, the subject does not hold a negative attitude (in this case) towards the particular act referred to by the demonstrative pronoun. Instead, in the case of "That is immoral", the subject disapproves of some property - call it $\mathrm{P}$ - and believes that $x$ (which represents what 'that' refers to) realizes $\mathrm{P}$. Thus, in declaring that murder is immoral,

\footnotetext{
${ }^{8}$ An anaphoric reference occurs when a word in a text refers to a previous idea in the text for its meaning. In the sentence "Fred always looked unkempt but this never seemed to bother him", the word 'him' clearly refers to Fred and therefore makes anaphoric reference to Fred.
} 
the subject holds a negative attitude towards $\mathrm{P}$ (some property yet to be described) and believes that an act of murder realizes P. Moreover, in stating that murder is immoral, the subject is not (should not be) declaring only that this token act of murder is immoral but, rather, that the type of action, of which this particular act is a token, - in virtue of realizing property $\mathrm{P}-$ is immoral. Where a different type of act realizes the same property, then one should disapprove of any token act of this action-type. If kidnapping, for example, realizes property $\mathrm{P}$ then, if one disapproves of murder (in virtue of property $\mathrm{P}$ ), one should disapprove of kidnapping, also.

So what is property P? Property P can and does amount to different things to different people. $S_{1}$ may view $\mathrm{P}$ in terms of negative utility - for example, the realizing of more displeasure than pleasure which is a posteriori discoverable - while $S_{2}$ may hold it to be a violation of God's law, or constitutive of a failure in one's duty to others. $S_{3}$, in turn, may characterize $\mathrm{P}$ as a vice rather than a virtue, and so on. Declaring that " $x$ is immoral" - where $x$ equates to murder - reveals the following:

(CEE) S disapproves of $\mathrm{P}$ and believes that $x$ realizes $\mathrm{P}$ (thus making anaphoric reference to that of which S disapproves).

Declaring that $x$ is immoral does not denote the truth of the proposition " $x$ is immoral"; rather, it denotes the truth of (a) S's disapproval of $\mathrm{P}$, and (b) S's belief that $x$ realizes $\mathrm{P} .{ }^{9}$

\footnotetext{
${ }^{9}$ In a slightly more complex version of the original ecumenical expressivism, (see Ridge, 2006), S's moral approval or disapproval is said to coincide with that of an ideal advisor. Where S disapproves of $x$, S's belief that $x$ realizes $\mathrm{P}$ is a belief that $x$ realizes some property that the ideal advisor disapproves of. What counts as an ideal advisor can vary. Where one's ideal advisor is a staunch advocate of God's law, S may disapprove of $x$ because $\mathrm{S}$ believes that $\mathrm{P}$, which is realized by $x$, amounts to a violation of God's law and so would be disapproved of by the ideal advisor. Alternatively, where S's ideal advisor adheres to utilitarian principles, $\mathrm{S}$
} 
In the context of single-player video games, where A declares "That is immoral" and B denies this, both $\mathrm{A}$ and $\mathrm{B}$ are expressing a moral attitude. A disapproves of that (whatever 'that' happens to be) and B does not. More specifically, A disapproves of $p$ and believes that that (whatever 'that' happens to be) realizes $p$ (thus making anaphoric reference to that of which A disapproves). Why does B not disapprove of that? (Before moving on, note that I have used the lowercase $p$ in italics to denote the specific property of which $\mathrm{A}$ in particular disapproves. This should be contrasted with the uppercase $\mathrm{P}$ used earlier, which refers to some unspecified property of which a subject disapproves. $)^{10}$

- When considering why B does not disapprove of that, it could be that both A and B disapprove of property $\mathrm{P}$ (where property $\mathrm{P}$ refers to the same thing). Nevertheless, it could also be that they are employing different interpretations of $x$ : the event within the game. How each interprets the virtual event $(x)$ will shape whether they come to believe that $x$ realizes $\mathrm{P}$. In this case, A does believe this, whereas B does not.

Alternatively, it could be that both A and B consider $x$ to be immoral. In other words, both agree that "That is immoral" in relation to the same virtual event. How might this be achieved?

- In this case, moral agreement (or shared moral attitude) is achieved because both believe that $x$ realizes some property $\mathrm{P}$ which they each disapprove of. It could be that $\mathrm{P}$ is the

may disapprove of $\mathrm{P}$ because it equates to negative utility, as disapproved of by the ideal advisor. This more complex version of ecumenical expressivism should not affect the argument for constructive ecumenical expressivism presented here.

${ }^{10}$ I thank the anonymous reviewer for drawing my attention to the need for terminological clarification here. 
same for both players. However, it could also be that what counts as property $\mathrm{P}$ is different in each case. Suppose A and B adopt a broad interpretation of the virtual event, $x$. Owing to the nature of their respective interpretations, A believes that $x$ realizes $p$ : where $p$ equates to commending one to delight in that which is immoral (the actual POTA the STA represents). B, on the other hand, does not believe $x$ realizes the property just described but still considers $x$ to be immoral because B interprets $x$ as realizing $q$, where $q$ equates to an increase in unpleasantness (increased negative affect/attitude/behaviour) which is something B disapproves of.

According to the explanation just described, both A and B consider $x$ to be immoral but for different reasons. It is not that A does not disapprove of something which causes increased unpleasantness, or that B does not disapprove of something which commends us to delight in the immoral; rather, it is that A does not believe that increased unpleasantness is a property realized by $x$, or does not prioritize it above a different property (commending one to delight in the immoral) which is held to be the main reason for A's moral disapproval. Mutatis mutandis, the same goes for B. After all, in the case of B, it is possible to believe that $x$ does not commend one to delight in the immoral but still believe it can lead to increased unpleasantness. Conversely, one can believe that $x$ commends us to delight in the immoral, and that this is reason enough for disapproval, irrespective of whether it causes an increase in unpleasantness. In short, in this scenario, both A and B express a negative attitude towards $x$ but for different reasons: that is, in virtue of believing that $x$ realizes some property $(\mathrm{P})$ which equates to something different in each case ( $p$ or $q$ ), but nevertheless serves the same reasongiving function. To illustrate: 
(CEE a) A disapproves of $p$ (where $p$ equates to commending one to delight in the immoral) and believes that $x$ realizes $p$ (thus making anaphoric reference to that of which A disapproves).

(CEE b) B disapproves of $q$ (where $q$ equates to increased unpleasantness) and believes that $x$ realizes $q$ (thus making anaphoric reference to that of which B disapproves).

In each case, the moral attitude towards $x$ is the same: namely, "it is wrong". This is because some property $(\mathrm{P})$, of which A (qua property $p$ ) and B (qua property $q$ ) disapprove, is believed by A and B, respectively, to be realized by $x$. There can be any number of reasons for one's attitude towards something. What constructive ecumenical expressivism teaches us is that moral attitude is no different.

Before continuing, a further point of clarification is required. To state that $\mathrm{A}$ and $\mathrm{B}$ have a shared attitude towards $x$, such that they both hold that $x$ is immoral, is to declare that they have the same de re attitude. When considering the act that A and B's attitude is directed towards (the intentional object), their attitude towards that act (the thing in itself) is the same. But this shared de re attitude exits in virtue of the belief that $x$ realizes some property $(\mathrm{P})$ which they both disapprove of, but which can be (and is) different for A and B: A believes that $x$ realizes $p$ and B believes it realizes $q$. Their differing belief about which property is realized by $x$ means that they have different reasons for their shared $d e$ re attitude. One could say that they have different de dicto attitudes regarding $x$ and hence the immorality of murder (namely, different beliefs about why it is immoral). ${ }^{11}$

\footnotetext{
${ }^{11}$ Again, I thank the anonymous reviewer for drawing my attention to this distinction.
} 


\subsection{What is constructed in constructive ecumenical expressivism?}

Like ecumenical expressivism, constructive ecumenical expressivism explains what the subject means when declaring that $x$ is immoral. By referring to property $\mathrm{P}$ as that of which one disapproves, the content of one's disapproval and with it the reason for one's disapproval of $x$ (which one believes realizes $\mathrm{P}$ ) can vary from subject to subject (or gamer to gamer). Importantly, what ecumenical expressivism does not provide, which constructive ecumenical expressivism does, is a means of identifying the 'correct' (qua most justified or even 'objectified') moral position regarding $x$ (one's de re attitude). It could also explain how (possibly) a shared de dicto attitude is achieved regarding $\mathrm{P}$, although this is not as important or even necessary for moral consensus.

What an endorsement of ecumenical expressivism entails, as the forerunner to the position I am prosing here, is the negation of moral realism; what it suggests is that established or alleged objective moral thinking is nothing but the elevation of one particular attitude over contrasting others. Yet it seems that in cases of prototypical POTAs such as murder or assault or torture or rape, to name a few, we do typically achieve moral consensus in the form of a shared de re attitude. Why, then, is moral consensus (likewise, in the form of a shared de re attitude) not forthcoming in the case of STAs which represent these prototypical POTAs?

\subsection{Constructive sentimentalism}

As a means of understanding how moral consensus (qua a shared de re attitude) has been achieved in the case of POTAs and, conversely, why it is absent in the case of STAs, I draw 
on Prinz's (2007) constructive sentimentalism. This is the view that although moral judgements stem from sentiment, or what Hume ([1739] 1978) refers to as feelings of disapprobation or approbation, they nevertheless form the basis for rules which have their own objective status within the socially constructed space they occupy (Copp, 2011, likens this view to what he calls realist expressivism; see also Copp, 2001). As Prinz states: "Things that we construct or build come from us, but, once there, they are real entities that we perceive" (2007, p.168). Prinz's position is compatible with the neo-sentimentalism proffered by Gibbard (1990), who argues that wrongful acts are judged to be so, not simply because one has a negative feeling towards the act but because such a feeling is appropriate. The addition of this normative element - that the negative feeling of guilt (for example) is not simply something we happen to feel but what we should feel - means, for Nichols (2008), that "even if one has lost any disposition to feel guilt about a certain action, one can still think that feeling guilty is warranted" (p.258; emphasis in original) within the socially constructed space one occupies. Nichols goes on to argue that the emotions we feel in relation to a given action have helped shape our cultural norms, by determining which are sustained and which are lost. His affective resonance hypothesis essentially states that: "Norms that prohibit actions to which we are predisposed to be emotionally averse will enjoy enhanced cultural fitness over other norms" (ibid., p.269).

\subsection{Constructing a shared moral attitude}

One can borrow from neo-sentimentalists like Prinz and argue for constructive ecumenical expressivism. Such a position is not incompatible with constructive sentimentalism; it does however have a wider scope owing to the fact that it does not describe moral utterances exclusively in terms of sentiment but, rather, in terms of one's attitude; although I accept that 
this may be shaped in part by some form of association with sentiment. As such, if it is the case that one ought to find $x$ immoral, in virtue of the fact that doing so is an established cultural norm (an objectification of the de re attitude towards $x$ in virtue of realizing some property $\mathrm{P}),{ }^{12}$ and as an individual I find $x$ moral or even amoral, and so out of step with the cultural norm, then it would seem that a change in my de re attitude is warranted.

In addition to providing a normative component to one's moral utterances, constructive ecumenical expressivism allows individuals or subgroups to share the same (de re) attitude with others (either other individuals or others within the same subgroup or even across different subgroups), but not necessarily for the same reasons (one may still have a different de dicto attitude to those with the same de re attitude). Thus, in the case of the following utterance - "Murder is immoral" - one can share with others one's disapproval of murder in virtue of the fact that it realizes some property $\mathrm{P}$, but disagree over what $\mathrm{P}$ is. Constructive ecumenical expressivism does not require that one has a negative moral attitude towards $x$ for the same reason as everyone else; rather, it demands only that one's de re attitude reflects the established cultural norm, irrespective of how, as an individual, it was acquired. If one's de re attitude does not reflect the cultural norm, then it does not make one's attitude untrue (for attitude lacks truth-aptness); rather, it makes it unwarranted (again, as dictated by the norm within the socially constructed space one occupies).

In the case of "Murder is immoral", I may share this de re attitude with a neighbour. Unlike my neighbour, however, I am not interested in what constitutes a violation of God's law and so cannot be said to have a disapproving de re attitude towards murder because it violates God's law. Despite our (de dicto) differences we express a shared negative (de re) attitude towards murder. How we (broadly) interpret the act leads us to draw the same

\footnotetext{
12 This position is able to provide the ideal advisor noted in the more complex version of ecumenical expressivism (see footnote 9) with a culturally shaped and socially endorsed status.
} 
conclusion regarding our approval or disapproval, even if how we (broadly) interpret the act differs in terms of our belief about certain properties it realizes, or how we prioritize these properties: a violation of God's law or something else (say, violating Kant's categorical imperative or increased negative utility, a vice rather than a virtue, etc.).

Moral consensus is forthcoming in the case of POTAs because POTAs realize a selection of properties at least one of which, but possibly more, the majority of people are willing to condemn, morally: e.g., negative utility, a violation of God's law or Kant categorical imperative, a vice rather than a virtue. In essence, with POTAs, if one endorses constructive ecumenical expressivism, such is the array of properties to disapprove of that it is simply a case of taking one's pick. In contrast, it is far less clear which properties are realized by STAs: for what counts as a correct interpretation, given the possibilities available under a broad interpretation, is more easily contested (as noted in Part 1). Therefore, which properties are genuinely realized by $x$ and which are genuinely available for one's disapproval is not so easy to establish. A lack of de re consensus regarding STAs is the result of an interpretational ambiguity regarding those properties available to approve or disapprove of. If one cannot agree on what that is then it becomes easier to see why we might find it harder to agree on whether that (whatever that is, broadly construed) is morally good or bad.

\subsection{What does consensus achieve?}

Having presented constructive ecumenical expressivism as a means of explaining why moral consensus is not forthcoming with regard to video game content (qua an agreed de re attitude), the way to moral consensus is perhaps now more illuminated. First, as an acceptance of constructive ecumenical expressivism negates moral realism, consensus cannot denote one's acceptance of a moral truth in the moral realist tradition; rather, for moral 
consensus to be achieved, one must acquire a shared moral attitude. Second, for one to acquire a shared moral attitude - let us say, in this case, a negative attitude - then one must interpret the virtual event $(x)$ in such a way as to concede that $x$ realizes some property $\mathrm{P}$ of which one disapproves. Where sufficient numbers accept that $x$ realizes $\mathrm{P}$ (even though what counts as $\mathrm{P}$ may vary between individuals) then one's (de re) attitude towards $x$ becomes warranted within that socially constructed space and a social norm is established and objectified, as in the case of POTAs and in the sense described by Prinz's constructive sentimentalism.

Returning to Postal 2 (or any game of that ilk), where one randomly murders a passerby. To be able to condemn morally such an STA, at least with justification, requires not only that one adopt a negative (de re) moral attitude towards the virtual event but also that one has established that such an attitude is warranted. To do this, one must interpret $x$ in such a way as to believe it realizes property $\mathrm{P}$ (a property one disapproves of). It is not necessary that everyone interpret $x$ in exactly the same way, only in a way that realizes some property that the individual in question disapproves of. By interpreting $x$ in this way - as realizing some property $\mathrm{P}$ that one (qua a given individual) disapproves of (which equates to their de dicto attitude) - a negative (de re) attitude towards $x$ is generated. When this is shared by others, to the point where it becomes established as a moral norm, it acts as an index of what is warranted and, in doing so, denotes what the moral attitude ought to be. Such a shared moral attitude - qua an objectified moral norm - although incapable of delineating a moral truth (which is not its intention, anyway), could nevertheless inform gaming industry and legislation with regard to morally appropriate content based on accepted norms.

\section{A few concluding remarks: Is an agreed moral position achievable?}


With reference to the content of single-player video games, as things stand, there is insufficient consensus in terms of interpretation and attitude (whether de dicto or de re) to establish a social norm that "That is immoral". A priori, there is no reason why a shared (de re) attitude could not prevail; although whether one will is ultimately an empirical question. What I hope to have achieved here is to have provided an explanation for why, at present, consensus is lacking and what is required for consensus to be achieved. For proponents of moral realism, no doubt constructive ecumenical expressivism is insufficiently robust, in terms of its depiction of what counts as a moral reason, to provide a credible normative account. As noted earlier, it was never my intention to defend my anti-realist position. If one accepts that there are no inherent moral truths, then I believe that ecumenical expressivism adequately explains why, typically, we have a shared (de re) moral attitude towards POTAs and why we do not in the case of their virtual counterparts within gamespace.

It could be, of course, that a particular moral position is adopted by legislators and even the gaming industry, without this being shared by the majority of gamers, or at least the majority of those who play video games of the kind discussed here. Where such a position is sincerely adopted (hypothetically speaking) - meaning that it does not occur simply as the result of obedience to an authority - then it is my contention that this is best explained by constructive ecumenical expressivism in terms of the legislators' and/or industries' shared (de re) attitude towards $x$ based on the belief that it realizes some property $\mathrm{P}$ that they disapprove of. Alternatively, such legislation may eventually come to reflect the shared attitude of the gaming and even wider community. While we are not at that point yet, should such an event occur then, once again, it is my belief that constructive ecumenical expressivism is in the best position to explain what is underpinning such consensus. 


\section{References}

Adachi, P.J.C., \& Willoughby, T. (2011). The Effect of Video Game Competition and Violence on Aggressive Behavior: Which Characteristic Has the Greatest Influence? Psychology of Violence, 1(4), 259-274.

Anderson, C. A. (2004). An update on the effects of violent video games. Journal of Adolescence 27, 113-122.

Anderson, C.A., Shibuya, A., Ihori, N., Swing, E.L., Bushman, B.J., Sakamoto, A., Rothstei, H.R., et al. (2010). Violent Video Game Effects on Aggression, Empathy, and Prosocial Behavior in Eastern and Western Countries: A Meta-Analytic Review. Psychological Bulletin 136(2), 151-173.

Bensley, L., \& Van Eenwyk, J. (2001). Video Games and Real-Life Aggression: Review of the Literature. Journal of Adolescent Health, 29, 244-257.

Boden, B.P., Breit, I., Beachler, J.A., Williams, A. \& Mueller, F.O. (2013). Fatalities in High School and College Football Players. The American Journal of Sports Medicine, 41(5), 11081116.

Bushman, B.J., \& Huesmann, L.R. (2014).Twenty-Five Years of Research on Violence in Digital Games and Aggression Revisited: A Reply to Elson and Ferguson (2013). European Psychologist, 19(1), 47-55. 
Bushman, B.J., Gollwitzer, M., \& Cruz, C. (2015). There Is Broad Consensus: Media Researchers Agree That Violent Media Increase Aggression in Children, and Pediatricians and Parents Concur. Psychology of Popular Media Culture, 4(3), 200-214.

Bushman, B.J., Rothstein, H.R., \& Anderson, C.A. (2010). Much Ado About Something: Violent Video Game Effects and a School of Red Herring: Reply to Ferguson and Kilburn (2010). Psychological Bulletin, 136(2), 182-187.

Collier, J.E., Liddell, P. Jr., \&, Liddell, G.J. (2008). Exposure of Violent Video Games to Children and Public Policy Implications. Journal of Public Policy \& Marketing, 27(1), 107112.

Copenhaver, A. (2015). Violent video game legislation as pseudo-agenda, Criminal Justice Studies: A Critical Journal of Crime, Law and Society, 28(2), 170-185.

Copp, D. (2001). Realist-Expressivism: A Neglected Option for Moral Realism. Social Philosophy and Policy, 18, 1-43.

Copp, D. (2011). Jesse Prinz, The Emotional Construction of Morals (Oxford: Oxford University Press, 2007): Prinz's Subjectivist Moral Realism. Nô̂s, 45(3), 577-594.

Di Muzio, G. (2006). The Immorality of Horror Films. International Journal of Applied Philosophy, 20(2), 277-294. 
Dretske, F. (1995). Naturalizing the Mind. Cambridge, Mass.: MIT Press.

Ferguson, C. J. (2007a). Evidence for publication bias in video game violence effects literature: A meta-analytic revie". Aggression and Violent Behavior, 12, 470-482.

Ferguson, C.J. (2007b). The good, the bad and the ugly: A meta-analytic review of positive and negative effects of violent video games. Psychiatric Quarterly, 78(4), 309-316.

Ferguson, C.J. (2008). The School Shooting/Violent Video Game Link: Causal Relationship or Moral Panic? Journal of Investigative Psychology and Offender Profiling, 5, 25-37.

Ferguson, C.J. (2010). Blazing Angels or Resident Evil? Can violent video games be a force for good? Review of General Psychology, 14(2), 68-81.

Ferguson, C.J. (2011). Video Games and Youth Violence: A Prospective Analysis in Adolescents. Journal of Youth and Adolescence, 40, 377-391.

Ferguson, C.J. (2013). Violent Video Games and the Supreme Court: Lessons for the Scientific Community in the Wake of Brown v. Entertainment Merchants Association. American Psychologist, 68(2), 57-74. 
Ferguson, C.J., \& Kilburn, J. (2010). Much Ado About Nothing: The Misestimation and Overinterpretation of Violent Video Game Effects in Eastern and Western Nations: Comment on Anderson et al. (2010). Psychological Bulletin, 136(2), 174-178.

Gibbard, A. (1990). Wise choices, apt feelings: A theory of normative judgment. Cambridge: Harvard University Press.

Greitemeyer, T., \& Mügge, O. (2014). Video games do affect social outcomes: A metaanalytic review of the effects of violent and prosocial video game play. Personality and Social Psychology Bulletin, 40(5), 578-589.

Huesmann, L.R. (2010). Nailing the Coffin Shut on Doubts That Violent Video Games Stimulate Aggression: Comment on Anderson et al. (2010). Psychological Bulletin, 136(2), $179-181$

Hume, D. (1978). A Treatise of Human Nature, L.A. Selby-Bigge (Ed.), 2nd edn. Oxford: Oxford University Press. (Originally published 1739)

Klimmt, C., Schmid, H., Nosper, A., Hartmann, T., \& Vorderer, P. (2006). How players manage moral concerns to make video game violence enjoyable. Communications, 31, 309328. 
Krahé, B. (2014). Restoring the Spirit of Fair Play in the Debate About Violent Video Games: A Comment on Elson and Ferguson (2013). European Psychologist, 19(1), 56-59.

Kreider , S.E. ( 2008 ). The virtue of horror films: A response to Di Muzio . International Journal of Applied Philosophy, 22, 149-157.

Lennon, J., \& Foley, M. (1996). JFK and Dark Tourism: A Fascination With Assassination. International Journal of Heritage Studies, 2(4), 198-211.

MailOnline (2007). Violent Manhunt computer game banned in UK for its 'casual sadism'. MailOnline, 20 June, 2007. Retrieved April 15, 2014 from:

http://www.dailymail.co.uk/news/article-463117/Violent-Manhunt-game-banned-UK-casual$\underline{\text { sadism.html }}$

Markey, P.M., \& Markey, C.N. (2010). Vulnerability to Violent Video Games: A Review and Integration of Personality Research. Review of General Psychology, 14(2), 82-91.

Markey, P. M., Markey, C. N., \& French, J. E. (2014). Violent Video Games and Real-World Violence: Rhetoric Versus Data. Psychology of Popular Media Culture, August, 1-19. http://dx.doi.org/10.1037/ppm0000030 
McCormick, M. (2001). Is it wrong to play violent video games? Ethics and Information Technology, 3(4), 277-287.

Moore, C.M., \& Brown, M. (2007). Experiencing Body Worlds: Voyeurism, Education, or Enlightenment? Journal of Medical Humanities, 28, 231-254.

Nauroth, P., Gollwitzer, M., Bender, J., \& Rothmund, T. (2014). Gamers against science: The case of the violent video games debate. European Journal of Social Psychology, 44, 104-116.

Nichols, S. (2008). Sentimentalism Naturalized. In W. Sinnott-Armstrong (Ed.) Moral Psychology: The Evolution of Morality, Volume 2 (pp. 255-274). Cambridge, Mass.: MIT Press.

Nys, T. (2010). Virtual Ethics. Ethical Perspectives 17(1), 79-93.

Poole, H. (1982 ). Obscenity and censorship. Ethics, 93, 39-44.

Powers, T.M. (2003). Real wrongs in virtual communities. Ethics in Information Technology $5,191-198$.

Prinz, J.J. (2007). The emotional construction of morals. Oxford: Oxford University Press. 
Ridge, M. (2006). Ecumenical Expressivism: Finessing Frege. Ethics, 116(2), 302-336.

Rothmund, T., Bender, J., Nauroth, P., \& Gollwitzer, M. (in press). Public concerns about violent video games are moral concerns - How moral threat can make pacifists susceptible to scientific and political claims against violent video games. European Journal of Social Psychology Available online at:

http://onlinelibrary.wiley.com.libezproxy.open.ac.uk/doi/10.1002/ejsp.2125/epdf

Schulzke, M. (2010). Defending the morality of violent video games. Ethics in Information Technology, 12(2), 127-138.

Shankar, P.R., Fields, S.K., Collins, CL., Dick, R.W., \& Comstock, D. R. (2007). Epidemiology of High School and Collegiate Football Injuries in the United States, 20052006. The American Journal of Sports Medicine, 35(8), 1295-1303.

Shoard, C. (2011). The Human Centipede sequel just too horrible to show, says BBFC. Guardian.co.uk, 6 June 2011. Retrieved $19^{\text {th }}$ May 2015 from: http://www.theguardian.com/film/2011/jun/06/human-centipede-sequel-bbfc

Singer, P. (2007). "Video crime peril vs. virtual pedophilia". The Japanese Times 22 July 2007. Retrieved $19^{\text {th }}$ May 2015 from: 
http://www.japantimes.co.jp/opinion/2007/07/22/commentary/world-commentary/video-

crime-peril-vs-virtual-pedophilia/\#.VVsxbt7bI5t

Sjöström, A., Sowka, A., Gollwitzer, M., Klimmt, C., \& Rothmund, T. (2013). Exploring Audience Judgments of Social Science in Media Discourse: The Case of the Violent Video Games Debate. Journal of Media Psychology, 25(1), 27-38.

Smith, B.K. (2006). Fight over Video Game Violence: Recent Developments in Politics, Social Science, and Law. Law \& Psychology Review, 30, 185-199.

Staiger, J. (2005). Media Reception Studies. New York: New York University Press.

Stone, P.R. (2006). A dark tourism spectrum: Towards a typology of death and macabre related tourist sites, attractions and exhibitions. Tourism: An International Interdisciplinary Journal, 54(2), 145-160.

Tait, S. (2008). Pornographies of Violence? Internet Spectatorship on Body Horror. Critical Studies in Media Communication, 25(1), 91-111.

Waddington, D.I. (2007). Locating the wrongness in ultra-violent video games. Ethics and Information Technology, 9(2), 121-128. 
Whitty, M.T., Young, G., \& Goodings, L. (2011). What I won't do in pixels: Examining the limits of taboo violation in MMORPGs. Computers in Human Behavior, 27(1), 268-275.

Young, G. (2013). Ethics in the Virtual World: The morality and psychology of gaming. Durham: Acumen.

Young, G. (2014). A meta-ethical approach to single-player gamespace: introducing constructive ecumenical expressivism as a means of explaining why moral consensus is not forthcoming. Ethics and Information Technology, 16(2), 91-102.

Young, G., \& Whitty, M. T. (2012). Transcending taboos: A moral and psychological examination of cyberspace. London: Routledge. 